\title{
Fast infectious diseases diagnostics based on microfluidic biochip system
}

\author{
Qin Huang \\ Department of Biomedical Engineering \\ The School of Medicine, Tsinghua University \\ Beijing 100084, P.R. China \\ National Engineering Research Center for Beijing Biochip Technology \\ Beijing 102206, P.R. China \\ Shanqiao Han \\ Center of Basic Medical Sciences \\ Navy General Hospital of Chinese PLA \\ Beijing 100048, P.R. China \\ Yan Zhang \\ National Engineering Research Center for Beijing Biochip Technology \\ Beijing 102206, P.R. China \\ The Collaborative Innovation Center for Diagnosis and Treatment of Infectious \\ Diseases, Hangzhou 310003, P.R. China \\ Yue Kou \\ National Engineering Research Center for Beijing Biochip Technology \\ Beijing 102206, P.R. China \\ Xiaohang Zhao* \\ Center of Basic Medical Sciences \\ Navy General Hospital of Chinese PLA \\ Beijing 100048, P.R. China \\ xhztao@126.com \\ Guoliang Huang* \\ Department of Biomedical Engineering \\ The School of Medicine, Tsinghua University \\ Beijing 100084, P.R. China \\ National Engineering Research Center for Beijing Biochip Technology \\ Beijing 102206, P.R. China \\ tshgl@tsinghua.edu.cn
}

${ }^{*}$ Corresponding authors.

This is an Open Access article published by World Scientific Publishing Company. It is distributed under the terms of the Creative Commons Attribution 4.0 (CC-BY) License. Further distribution of this work is permitted, provided the original work is properly cited. 
Received 2 February 2016

Accepted 22 May 2016

Published 7 July 2016

\begin{abstract}
Molecular diagnostics is one of the most important tools currently in use for clinical pathogen detection due to its high sensitivity, specificity, and low consume of sample and reagent is keyword to low cost molecular diagnostics. In this paper, a sensitive DNA isothermal amplification method for fast clinical infectious diseases diagnostics at aM concentrations of DNA was developed using a polycarbonate (PC) microfluidic chip. A portable confocal optical fluorescence detector was specifically developed for the microfluidic chip that was capable of highly sensitive real-time detection of amplified products for sequence-specific molecular identification near the optical diffraction limit with low background. The molecular diagnostics of Listeria monocytogenes with nucleic acid extracted from stool samples was performed at a minimum DNA template concentration of $3.65 \mathrm{aM}$, and a detection limit of less than five copies of genomic DNA. Contrast to the general polymerase chain reaction (PCR) at eppendorf (EP) tube, the detection time in our developed method was reduced from $1.5 \mathrm{~h}$ to $45 \mathrm{~min}$ for multi-target parallel detection, the consume of sample and reagent was dropped from $25 \mu \mathrm{L}$ to $1.45 \mu \mathrm{L}$. This novel microfluidic chip system and method can be used to develop a micro total analysis system as a clinically relevant pathogen molecular diagnostics method via the amplification of targets, with potential applications in biotechnology, medicine, and clinical molecular diagnostics.
\end{abstract}

Keywords: Microfluidic chip; real-time fluorescent detector; clinical pathogen molecular diagnostics; sequence-specific molecular identification.

\section{Introduction}

Infectious diseases account for more than half of child deaths worldwide, and one in nine child deaths are caused by diarrhea, making diarrhea the second leading cause of death among children under the age of five. ${ }^{1}$ A fundamental requirement for successful disease control is to diagnose pathogens to guide the timely and appropriate treatment and development of effective interventions such as vaccines. ${ }^{2}$ Clinically, point-of-care diagnostics for the identification of diarrhea pathogens is mainly based on bacterial culture, ELISAs, and molecular techniques. ${ }^{3}$ The conventional bacterial culture method is still used as the gold standard for pathogen identification, but the process usually takes several days to complete. ${ }^{4}$ ELISA is rapid and precise, but its application is limited by the availability of pure antigens and subsequent production of specific antibodies. ${ }^{5}$ Nucleic acid amplification-based methods are preferred because they enable the accurate identification of target nucleic acid sequences with high sensitivity and specificity, and nucleic acid amplification methods are less time consuming and less vulnerable to cross-contamination. Among these methods, polymerase chain reaction (PCR) is most commonly used. ${ }^{6}$ Nevertheless, the use of PCR is limited by thermal constraints, with precise threestage temperature control and a fast transition between stages required. There are isothermal amplification methods have been developed to overcome the drawbacks of PCR, which mainly consist of loop-mediated isothermal amplification (LAMP), ${ }^{7}$ nucleic acid sequence-based amplification (NASBA), ${ }^{8}$ strand displacement amplification (SDA), ${ }^{9}$ and rolling circle amplification (RCA).${ }^{10}$ Among these, LAMP has attracted considerable interest because it can be implemented with a single enzyme (strand displacing polymerase) using simple electrodes or heating elements. ${ }^{11}$

Because there is no need for thermal cycling steps for LAMP, recent efforts have aimed to apply LAMP assays in resource-poor areas. Aside from conventional PCR tubes, attempts have been made to develop microfluidic chips integrated with LAMP for gene analysis ${ }^{12}$ : Wang et al. present an automatic assay for targeted ribonucleic acid (RNA) extraction and a one-step reverse transcription LAMP (RT-LAMP) process for the detection of 
viruses from tissue samples by utilizing an integrated microfluidic system. ${ }^{13}$ Ahmad et al. report a charge-coupled device (CCD)-based fluorescence imaging system for detection of waterborne pathogens by isothermal gene amplification in disposable microchips. ${ }^{14}$ Myers et al. develop a device named the microfluidic biomolecular amplification reader (mBAR), which is capable of performing isothermal nucleic acid amplification assays with real-time fluorescence readout. ${ }^{15}$ Luo et al. demonstrate a microfluidic multiplex electrochemical LAMP $(\mu \mathrm{ME}-\mathrm{LAMP})$ system for real-time quantitative differentiation of bacteria. ${ }^{16}$ Sun et al. describe an eight-chamber lab-on-a-chip (LOC) system with integrated magnetic bead-based sample preparation and LAMP for detection of Salmonella spp. in food samples. ${ }^{17}$ Borysiak et al. report the nucleic acid isotachophoresis LAMP (NAIL) diagnostic device, which uses isotachophoresis (ITP) and LAMP inside an integrated chip. ${ }^{18}$ These microfluidic chips decrease the time necessary for DNA amplification, consume less sample and reagents, and increase portability, compactness, and the potential for automation of analyses. ${ }^{19-23}$

Despite the fact that various LAMP-based microfluidic chips have been developed for rapid detection and identification of bacteria and viruses, portable platforms for point-of-care testing are still in the initial stages of development. Indeed, microfluidic chips for real-time multiple samples and multiple index diagnosis in a single detection run have seldom been reported. The aim of this work was to describe a real-time LAMP-integrated microfluidic chip system for the identification of the diarrhea pathogenic bacteria Listeria monocytogenes. In addition, the sensitivity, specificity, and reproducibility of the chips were evaluated. The performance of this method was compared with traditional microbiological methods and PCR assays.

\section{Materials and Methods}

\subsection{Samples and DNA extraction methods}

Thirty clinical stool samples and the standard bacterial strain Listeria monocytogenes strain ATCC 19115 were obtained from the Navy General Hospital of Chinese PLA (Beijing, China). All samples and strain were identified using standard biochemical isolate tests. Bacterial DNA was extracted from all clinical samples using a QIAamp Fast DNA Stool Mini Kit (Qiagen Inc., CA, USA) according to the manufacturer's instructions. Genomic DNA from the standard strain was extracted and purified using a QIAamp DNA Mini Kit (Qiagen Inc., CA, USA). The concentration and quality of DNA were measured using an ND-1000 Spectrophotometer (NanoDrop Technologies, Inc., DE, USA) by spectrophotometric analysis at $260 \mathrm{~nm}$ and $280 \mathrm{~nm}$. Then, PCR assays that targeted the $16 \mathrm{~S}$ rDNA for amplification were used for bacterial validation.

\subsection{Primer design}

Oligonucleotide primers were designed for the isothermal amplification assay according to the sequences of the hlyA gene from Listeria monocytogenes (Gen-Bank accession no. HM589604) using Primer Explorer version 4 (https://primerexplorer.jp/elamp4.0.0/index.html). The directions and details of the primers are shown in Table 1. All of the oligonucleotide primers were synthesized by Invitrogen (Shanghai, China).

\subsection{Isothermal amplification assay}

The $10 \mu \mathrm{L}$ isothermal nucleic acid amplification assays for pathogen molecular diagnostics consisted of $0.2 \mu \mathrm{M}$ each of primers F3 and B3, 1.6 $\mu \mathrm{M}$ each

Table 1. Sequences of primer sets for Listeria monocytogenes identification.

\begin{tabular}{llc}
\hline Bacteria & Primers & Sequence $\left(5^{\prime}-3^{\prime}\right)$ \\
\hline Listeria monocytogenes & Lmo-F3 & ACTTCGGCGCAATCAGT \\
& Lmo-B3 & GGCAGCATCAAAAGCAG \\
Lmo-FIP & AAGGTCTTGTAGGTTCATTAACAGAAGGGAAAATGCAAGAAGAAGT \\
Lmo-BIP & TCGGCAAAGCTGTTACTAAAGAGCCACACTTGAGATATATGCAGG \\
Lmo-LF & TCACGTTATAGTAAATTTGTTTAAA \\
Lmo-LB & TTGGAGTGAATGCAGAAAAT \\
\hline
\end{tabular}


of FIP and BIP, $0.4 \mu \mathrm{M}$ each of LF and LB, $8 \mathrm{U}$ of Bst DNA Polymerase, Large Fragment, $0.1 \mathrm{mM}$ dUTP, $0.4 \mathrm{mM}$ dNTPs (New England Biolabs Ltd, Beverly, USA), $0.5 \mathrm{mg} / \mathrm{mL}$ BSA (Fluka SigmaAldrich Inc, Missouri, USA), $0.6 \times$ EvaGreen (Biotium Inc, California, USA), $0.8 \mathrm{M}$ betaine (Fluka Sigma-Aldrich Inc, Missouri, USA), $6 \mathrm{mMMgSO}_{4}$ (Beijing Chemical Reagents Company, Beijing, China), 0.1 U/mL Uracil-DNA Glycosylase (Fermentas Inc, Burlington, Canada), $10 \mathrm{mM}$ $\left(\mathrm{NH}_{4}\right)_{2} \mathrm{SO}_{4}, 20 \mathrm{mM}$ Tris- $\mathrm{HCl}\left(\mathrm{pH} 8.8\right.$ at $\left.25^{\circ} \mathrm{C}\right)$, $10 \mathrm{mM} \mathrm{KCl}, 0.1 \%$ Triton X-100, and template DNA $(2 \mu \mathrm{L})$. The reaction mixtures were incubated at $37^{\circ} \mathrm{C}$ for $5 \mathrm{~min}$, then heated to $65^{\circ} \mathrm{C}$ and kept at a constant temperature of $65^{\circ} \mathrm{C}$ for $40-45 \mathrm{~min}$ before ultimately heating to $80^{\circ} \mathrm{C}$ for $5 \mathrm{~min}$ to terminate the reaction.

\subsection{Microfluidic chip fabrication}

Disc-type microfluidic chips, as shown in Fig. 1(a), were fabricated from polycarbonate $(\mathrm{PC})$ material using a computer numerical control machining center. The chips consisted of an array of 24 reaction wells with a diameter of $60 \mathrm{~mm}$ and thickness of $1.2 \mathrm{~mm}$. The volume of each bioreactor was $\sim 1.45 \mu \mathrm{L}$. Both the width and the depth of the channels were $0.1 \mathrm{~mm}$. Each bioreactor was closely connected to a buffer well with a diameter of $2.0 \mathrm{~mm}$ and depth of $0.2 \mathrm{~mm}$. The buffer well was connected with the crooked primary channel. When the chip was heated, the slim capillary channels were cut off by the thermal stresses, thus isolating the bioreactors to reduce possible contamination among bioreactors. The diameters of both the inlet and outlet were $1.2 \mathrm{~mm}$, which fit a micropipette tip to load reagents and sample by the eppendorf (EP) head. The positioning hole in the center of the chip was used to fasten the chip to the motor of the detection system. The chip was composed of three layers: (1) the PC plate where the bioreactor, channel, buffer cell, inlet, outlet, and fixed hole were produced; (2) the top surface of the microfluidic chip, which was inert to DNA molecules; and (3) a thin PC film tightly affixed to the surface of the microfluidic chip for encapsulation.

When the microfluidic chip was used, all primers were first printed in the different bioreactors with a homemade sampling apparatus and covered by gelose gelatin as in Fig. 1(b); the positive and negative controls were staggered among the bioreactors containing the primers. Sterilized DNA-free $\mathrm{ddH}_{2} \mathrm{O}$ was used as a negative control (NC). An inner positive control was used to indicate the performance of the reagents, chip fabrication, and running of the setup for on-chip LAMP. Second, the mixtures of the biological reagents and DNA samples were injected into the bioreactors of the micro fluidic chip from the inlet using an EP pipette $(200 \mu \mathrm{L})$, and then the inlet and outlet were sealed with a thin PC film. Third, all mixtures in the channels were centrifuged at a speed of $6000 \mathrm{rpm}$ to move the mixtures into the bioreactors and empty the channels. The channel between any two adjacent bioreactors was obstructed by heating compression to keep all bioreactors independent of each other during the isothermal amplification process. Finally, the chip was placed in a homemade

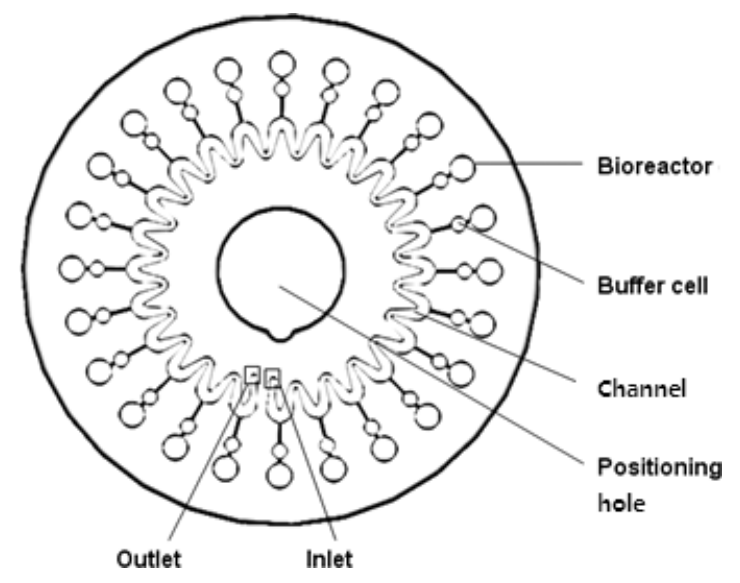

(a)

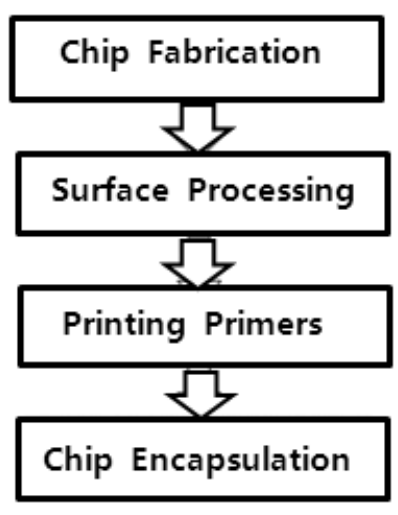

(b)

Fig. 1. Structure of the microfluidic chip. 
detector and heated to $65^{\circ} \mathrm{C}$ for real-time fluorescence detection. When heated, the gelose gelatin melted and the primers were released into the bioreactors to initiate isothermal nucleic acid amplification. In a typical test, 90 detection cycles was finished within $45 \mathrm{~min}$, and the real-time fluorescent curves corresponding to every bioreactor were obtained from the detector for bacterial molecular diagnostics.

\subsection{Portable confocal optical fluorescence detector}

To detect the DNA amplification in the microfluidic chips with high sensitivity and low background, a homemade portable real-time confocal detector was developed as shown in Fig. 2. An objective set L1 with a focal length of $13 \mathrm{~mm}$ and numerical aperture of NA $=0.72$ was designed. The excited light from a blue LED was first collimated by a spherical lens L1 and filtered by the band pass filter F1 with a central wavelength of $470 \mathrm{~nm}$ and bandwidth of $20 \mathrm{~nm}$. Then, the excited light was focused by the objective set L2 to illuminate the bioreactors of the micro fluidic chip MC on the rotary scanning motor. The intensity of the excited light was adjusted to adapt to the different applications of the chip by the attenuator A1. A dichroic mirror D1 was used to reflect the fluorescence from the bioreactor and to penetrate the excited light from the LED. The fluorescence from Eva Green intercalating into the double-stranded DNA in the bioreactor cell was excited by the LED and initially collected by the objective set L2, reflected by D1, and focused on the detector PMT (HAMAMATSU, Japan) by the imaging lens set L3 with a focal length of $22 \mathrm{~mm}$.
A filter F2 with a $525 \mathrm{~nm}$ central wavelength and $40 \mathrm{~nm}$ bandwidth was used to penetrate the fluorescence and limit the excited light. The pinhole $(\mathrm{PH})$ was used to filter the farraginous light from the environment and the off-focused fluorescence from the material of the microfluidic chip. Finally, the fluorescence signal was transferred to a computer by an A/D processor. The temperature controller PID was used to administer the heater $\mathrm{HF}$ with the accuracy of $0.1^{\circ} \mathrm{C}$ and speed of raising the temperature of $1^{\circ} \mathrm{C} / \mathrm{s}$ by the temperature feedback of sensor $\mathrm{S}$ during DNA isothermal amplification. A multiple-axis moving driver (MAMD) was used to supervise the rotary scanning motor with an angle accuracy of $0.1^{\circ}$.

\section{Results and Discussion}

\subsection{Sensitivity and quantification anal- ysis of the isothermal amplification assay on the microfluidic chip}

The sensitivity of the isothermal amplification assay on the microfluidic chip was assessed using genomic DNAs (gDNAs) of Listeria monocytogenes. Ten different DNA template samples $\left(1.0 \times 10^{5}, 1.0 \times 10^{4}, 1.0 \times 10^{3}, 1.0 \times 10^{2}, 1.0 \times\right.$ $10^{1}, 5$ copies, 4 copies, 3 copies, 2 copies and 1 copy) were used, and a blank was used as negative control. The amplification curves are displayed in Fig. 3. Twenty-four duplications were performed for every DNA template concentration in one chip. The time to positive value $(T p)$, which was defined as the time at the second derivative inflexion of the exponential DNA amplification curve, was set to indicate the initiation of the entire system. As shown

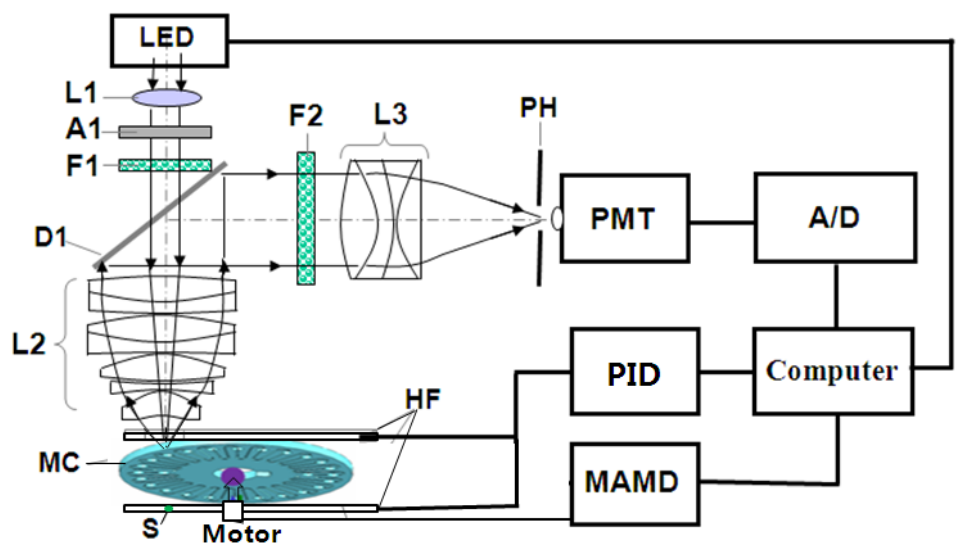

Fig. 2. Structure of the portable confocal optical fluorescence detector. 
Q. Huang et al.

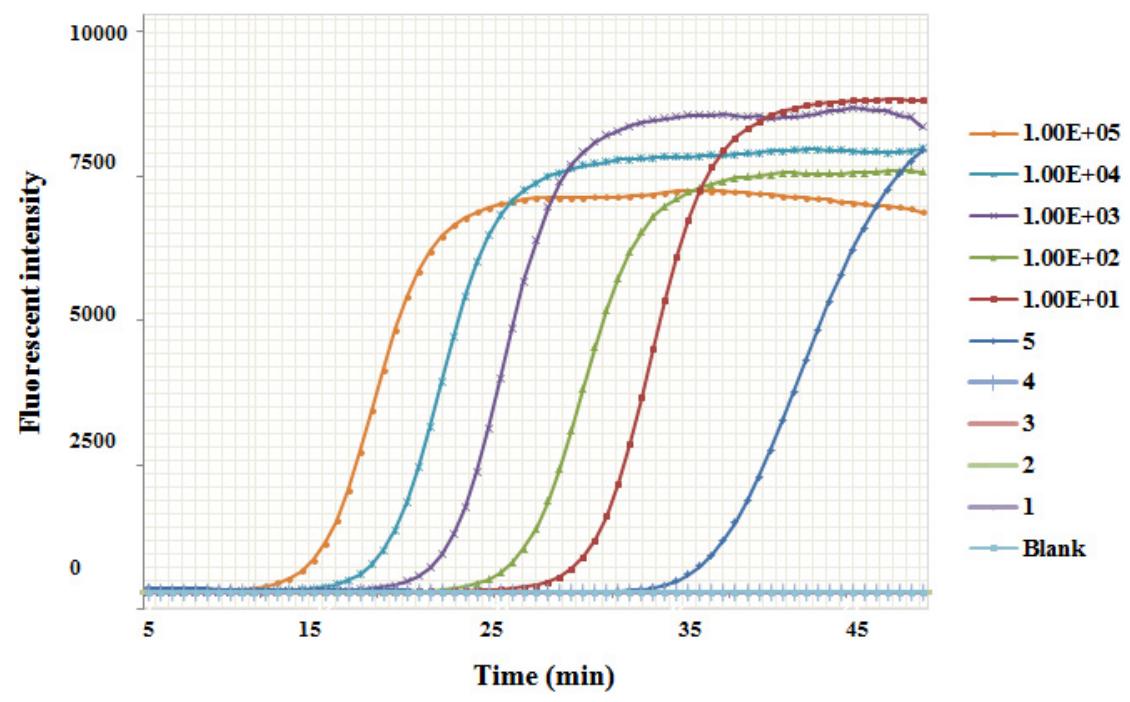

(a)

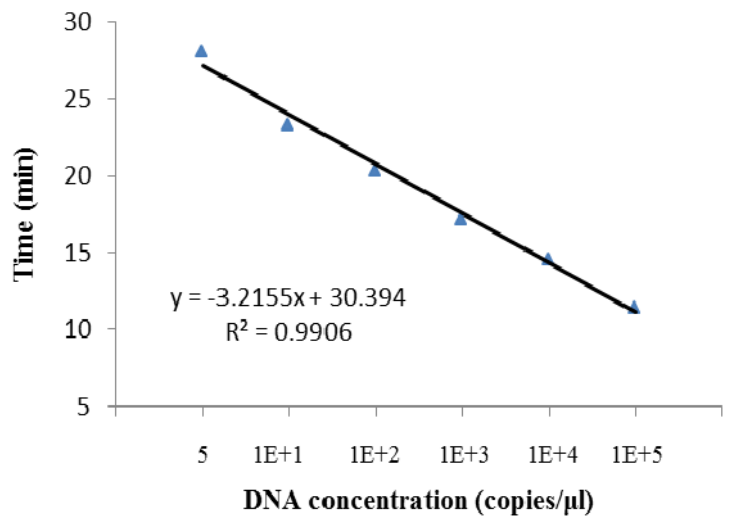

(b)

Fig. 3. (a) Sensitivity analysis of the isothermal amplification assay on the microfluidic chip. (b) Quantification analysis of the isothermal amplification assay on the microfluidic chip.

in Fig. 3(a), the limit of detection for isothermal amplification was five copies $(2.3 \mathrm{pg} / \mu \mathrm{L}=3.65 \mathrm{aM})$ of Listeria monocytogenes gDNA, and nucleic acid copies which below this concentration offered no signal. The coefficients of variation $(\mathrm{CVs})$ of 24 repeated measurements for a same nucleic acid concentration were $2.93 \%, 1.28 \%, 1.62 \%, 2.76 \%$ and $3.6 \%$ for DNA concentrations of $1.0 \times 10^{1}$, $1.0 \times 10^{2}, 1.0 \times 10^{3}, 1.0 \times 10^{4}, 1.0 \times 10^{5}$, respectively, indicating that the $T p$ value for most of the tested bacteria was slightly variable. The average $T p$ value was $28 \mathrm{~min}, 23 \mathrm{~min}, 20 \mathrm{~min}, 17 \mathrm{~min}$ and $14 \mathrm{~min}$ for the above samples, respectively. And the $P$ value among these six positive groups was less than 0.01 , showing a dramatically difference between gradient DNA concentrations. Moreover, there was a linear relationship between the $T p$ value and the bacterial gDNA concentration (Fig. 3(b)). The regression coefficient square $\left(R^{2}\right)$ was 0.9906 for Listeria monocytogenes. This indicated that the microfluidic chip amplification system was able to quantify the bacteria.

\subsection{Specificity analysis of the isothermal amplification assay on the microfluidic chip}

The specificity of the parallel detection of multiple bacteria on the microfluidic chip was determined using gDNAs from six bacteria with desired concentrations for each bacterium $\left(1.0 \times 10^{4}\right.$ copies $)$, 


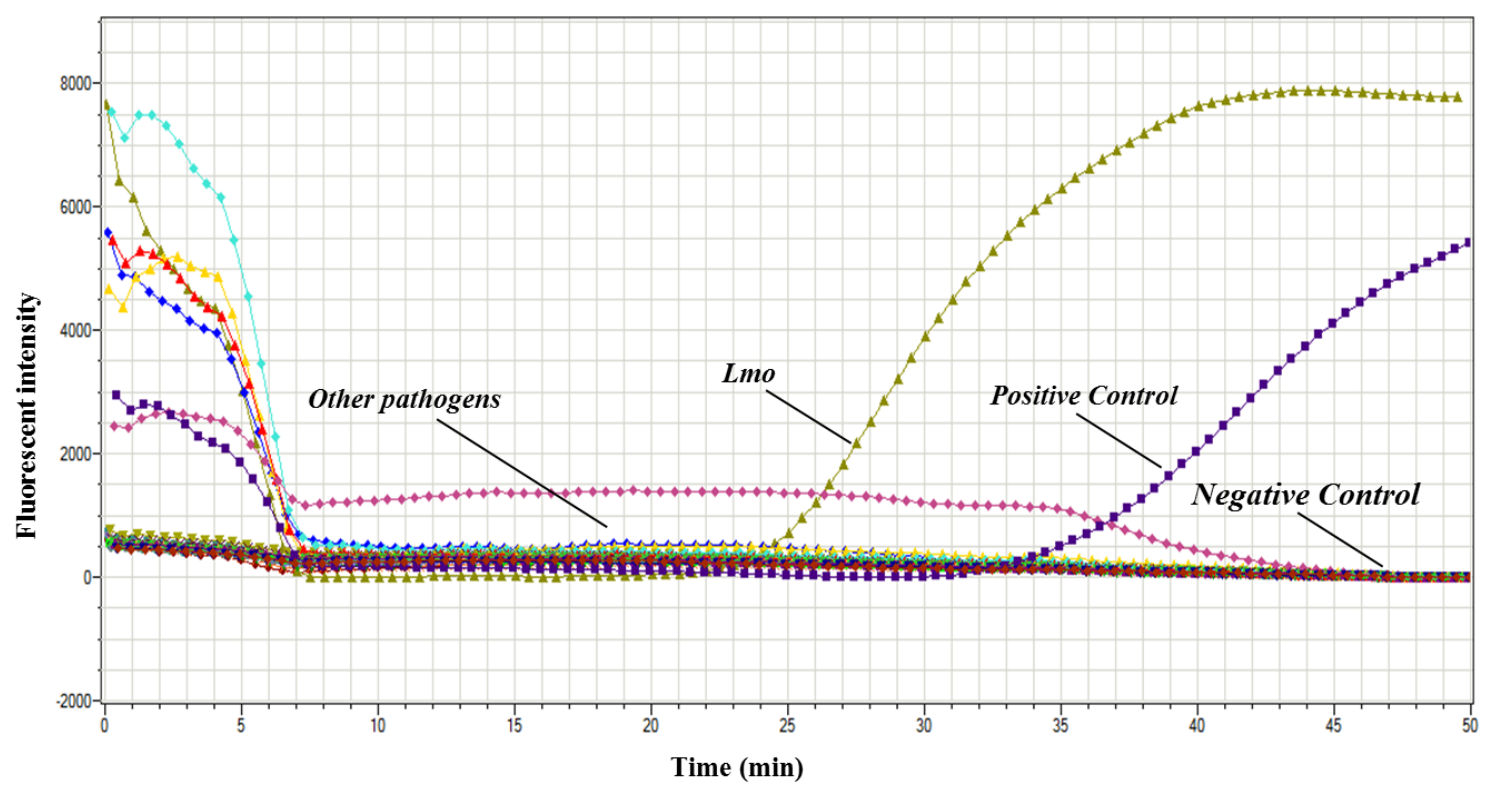

Fig. 4. Specificity analysis of the isothermal amplification assay on the microfluidic chip.

including the target bacteria in this study and five others, i.e., Shigella flexneri, Salmonella typhimurium, Vibrio parahaemolyticus, and Vibrio alginolyticus, Vibrio vulnificus. The expected positive signal was observed as a typical sigmoidal amplification curve (Fig. 4), indicating that the isothermal amplification chip was suitable for parallel detection of multiple bacteria. The data revealed that no cross-reactions were obtained among the six species, indicating high specificity among different primer sets. The negative control (no primers dispensed in the reaction well) showed no fluorescence throughout the amplification, indicating the low signal background and absence of contamination. All tests were repeated six times. The $P$ value for the six tests was 1.00, declaring no variance between the six repetitions of the same sample.

\subsection{Clinical sensitivity and specificity of the isothermal amplification assay on the microfluidic chip}

A total of 30 stool samples were first assessed by conventional bacterial culture methods as standards and then by the isothermal amplification assay on the microfluidic chip and PCR, followed by DNA sequencing. In brief, of the target diarrhea pathogenic bacteria tested in our microfluidic chip, the number of samples confirmed to be positive for
Listeria monocytogenes by the culture method was four. The remaining 26 samples were found to be negative for Listeria monocytogenes. Among the four positive isolates, except for coincident samples, one additional Listeria monocytogenes-negative sample was confirmed using our microfluidic chip. The reason for this negative sample is due to the sequence-based principle of our technique. In other words, our microfluidic chip assay may yield a false negative result if the bacterium lacks our target gene, i.e. the Listeria monocytogenes isolate may carry no hlyA gene. Overall, the microfluidic chip method exhibited $80 \%$ clinical sensitivity, $96.97 \%$ clinical specificity, $3.33 \%$ false negative and no false positive compared to conventional culture methods (Table 2).

Table 2. Clinical sensitivity and specificity of the isothermal amplification assay on the microfluidic chip.

\begin{tabular}{lcccc}
\hline & \multicolumn{3}{c}{$\begin{array}{c}\text { Microfluidic } \\
\text { chip }\end{array}$} & $\begin{array}{c}\text { 16 DNA } \\
\text { sequencing sequencing }\end{array}$ \\
\hline $\begin{array}{l}\text { Listeria } \\
\text { monocytogenes }\end{array}$ & 5 & 4 & 5 & 4 \\
$\quad$ positive & & & 25 & 26 \\
$\begin{array}{l}\text { Listeria } \\
\text { monocytogenes }\end{array}$ & 25 & 26 & & \\
$\quad$ negative & & & & \\
$\begin{array}{l}\text { Clinical sensitivity } \\
\text { Clinical specificity }\end{array}$ & & $80 \%$ & & \\
\hline
\end{tabular}




\section{Conclusion}

In the present study, a microfluidic chip assay and real-time detector system for multiplex detection of the diarrhea pathogenic bacteria Listeria monocytogenes in stool samples was developed. Following a simple one-off operation loading of template DNA in the inlet hole on the chip, which remarkably simplifies the process, the analysis can be rapidly accomplished within $45 \mathrm{~min}$. Compared to other conventional techniques, the developed microfluidic chip assay and real-time detection system achieves almost the high sensitivity to 3.65 aM DNA template concentration and good specificity for the detection of pathogens in field samples, the detection time is about $45 \mathrm{~min}$ and the consume of sample and reagent is $1.45 \mu \mathrm{L}$, it is also lower cost and less labor. The microfluidic chip assay provides a convenient platform for on-site detection and routine monitoring of pathogens causing diarrhea diseases. It is necessary to complement this technique with others that may detect other relevant microorganisms, and further field tests will help optimize its use in clinical applications.

\section{Acknowledgment}

This work was supported by the National Natural Science Foundation of China (81327005, $61361160418,61575100)$, the National Foundation of High Technology of China (2012 AA020102, 2013 AA041201), the National Key Foundation for Exploring Scientific Instruments (2013 YQ190467), the Beijing Municipal Natural Science Foundation (4142025), the Beijing Lab Foundation, and the Tsinghua Autonomous Research Foundation (2014 Z01001). Qin Huang and Shanqiao Han contributed equally to this work.

\section{References}

1. L. Liu, H. L. Johnson, S. Cousens, J. Perin, S. Scott, J. E. Lawn, I. Rudan, H. Campbell, R. Cibulskis, M. Li, C. Mathers, R. E. Black, Child Health Epidemiology Reference Group of WHO and UNICEF, "Global, regional, and national causes of child mortality: An updated systematic analysis for 2010 with time trends since 2000," External Web Site Icon Lancet 379(9832), 2151-2161 (2012).

2. A. M. Caliendo, D. N. Gilbert, C. C. Ginocchio, K. E. Hanson, L. May, T. C. Quinn, F. C. Tenover,
D. Alland, A. J. Blaschke, R. A. Bonomo, K. C. Carroll, M. J. Ferraro, L. R. Hirschhorn, W. P. Joseph, T. Karchmer, A. T. MacIntyre, L. B. Reller, A. F. Jackson, Infectious Diseases Society of America (IDSA), "Better tests, better care: Improved diagnostics for infectious diseases," Clin. Infect. Dis. $\mathbf{5 7}$ (suppl 3), S139-S170 (2013).

3. J. Liu, F. Kabir, J. Manneh, P. Lertsethtakarn, S. Begum, J. Gratz, S. M. Becker, D. J. Operario, M. Taniuchi, L. Janaki, J. A. Platts-Mills, D. M. Haverstic, M. Kabir, S. U. Sobuz, K. Nakjarung, P. Sakpaisal, S. Silapong, L. Bodhidatta, S. Quresh, A. Kalam, Q. Saidi, N. Swai, B. Mujaga, A. Maro, B. Kwambana, M. Dione, M. Antonio, G. Kibiki, C. J. Mason, R. Haque, N. Iqbal, A. K. M. Zaidi, E. R. Houpt, "Development and assessment of molecular diagnostic tests for 15 enteropathogens causing childhood diarrhoea: A multicentre study," Lancet Infect. Dis. 14(8), 716-724 (2014).

4. T. S. Hammack, I. E. Valentin-Bon, A. P. Jacobson, W. H. Andrews, "Relative effectiveness of the bacteriological analytical manual method for the recovery of Salmonella from whole cantaloupes and cantaloupe rinses with selected preenrichment media and rapid methods," J. Food Prot.. 67(5), 870-877 (2004).

5. A. D. S. Schneid, K. L. Rodrigues, D. Chemello, E. C. Tondo, M. A. Z. Ayub, J. A. G. Aleixo, "Evaluation of an indirect ELISA for the detection of Salmonella in chicken meat," Braz. J. Microbiol. 37(3), 350-355 (2006).

6. R. K. Saiki, S. Scharf, F. Faloona, K. B. Mullis, G. T. Horn, H. A. Erlich, N. Arnheim, "Enzymatic amplification of $\beta$-globin genomic sequence and restriction site analysis for diagnosis of sickle cell anemia," Science 230(4732), 1350-1354 (1985).

7. N. Tsugunori, O. Hiroto, M. Harumi, Y. Toshihiro, W. Keiko, A. Nobuyuki, H. Tetsu, "Loop-mediated isothermal amplification of DNA," Nucl. Acids Res. 28(12), e63 (2000).

8. J. Compton, "Nucleic acid sequence-based amplification," Nature. 350(6313), 91-92 (1991).

9. G. T. Walker, M. S. Fraiser, J. L Schram, M. C. Little, J. G. Nadeau, D. P. Malinowski, "Strand displacement amplification-an isothermal in vitro DNA amplification technique," Nucl. Acids Res. 20(7), 1691-1696 (1992).

10. D. Liu, S. M. Daubendiek, K. R. Zillman, E. J. Kool, "Rolling circle DNA synthesis: Small circular oligonucleotides as efficient templates for DNA polymerases," Am. Chem. Soc.. 118(7), 1587-1594 (1996).

11. Y. Mori, T. Notomi, "Loop-mediated isothermal amplifi cation (LAMP): A rapid, accurate, and costeffective diagnostic method for infectious diseases," J. Infect. Chemother. 15(2), 62-69 (2009). 
12. A. M. Foudeh, T. F. Didar, T. Veres, M. Tabrizian, "Microfluidic designs and techniques using lab-ona-chip devices for pathogen detection for point-ofcare diagnostics," Lab Chip 12(18), 3249-3266 (2012).

13. C. H. Wang, K. Y. Lien, T. Y. Wang, T. Y. Chen, G. B. Lee, "An integrated microfluidic loop-mediated-isothermal-amplification system for rapid sample pre-treatment and detection of viruses," Biosens. Bioelectron. 26(5), 2045-2052 (2011).

14. F. Ahmad, G. Seyrig, D. M. Tourlousse, R. D. Stedtfeld, J. M. Tiedje, S. A. Hashsham, "A CCDbased fluorescence imaging system for real-time loop-mediated isothermal amplification-based rapid and sensitive detection of waterborne pathogens on microchips," Biomed. Microdev. 13(5), 929-937 (2011).

15. B. M. Frank, H. H. Richard, B. Jennifer, P. L. Luke, "A Handheld Point-of-Care Genomic Diagnostic System" PLOS One, 8(8), e70266 (2013).

16. J. Luo, X. Fang, D. X. Ye, H. X. Li, H. Chen, S. Zhang, J. L. Kong, "A real-time microfluidic multiplex electrochemical loop-mediated isothermal amplification chip for differentiating bacteria," Biosens. Bioelectron. 60, 84-91 (2014).

17. Y. Sun, T. L. Quyen, T. Q. Hung, W. H. Chin, A. Wolff, D. D. Bang, "A lab-on-a-chip system with integrated sample preparation and loop-mediated isothermal amplification for rapid and quantitative detection of Salmonella spp. in food samples," Lab Chip. 15(8), 1898-1904 (2015).

18. D. B. Mark, W. K. Kevin, D. P. Jonathan, "NAIL: Nucleic Acid detection using Isotachophoresis and Loop-mediated isothermal amplification," Lab Chip 15(7), 1697-1707 (2015).

19. G. Huang, X. Yang, J. Zhu, S. Xu, C. Deng and C. Han, Detection and application of microfluid isothermal amplification on chip, Journal of Innovative Optical Health Sciences (JIOHS) 1(2), 257-265 (2008).

20. G. Huang, Q. Huang, L. Ma, X. Luo, B. Pang, Z. Zhang, R. Wang, J. Zhang, Q. Li, R. Fu and J. Ye, fM to aM nucleic acid amplification for molecular diagnostics in a non-stick-coated metal microfluidic bioreactor, Scientific Reports 4(7344), 1-9 (2014).

21. W. TongZhou, Z. Ye, H. GuoLiang, W. Can, X. Lan, M. Li, L. ZhiYong, L. XianBo, T. Hao, L. Qiang, L. Xin, L. ZhouYan and B. XiaoFan, Detect early stage lung cancer by a LAMP microfluidic chip system with a real-time fluorescent filter processor, Science China Chemistry 55(4), 508-514 (2012).

22. G. Huang, C. Wang, L. Ma, X. Yang, X. Yang and G. Wang, Sensitive sequence-specific molecular identification system comprising an aluminum micro-nanofluidic chip and associated real-time confocal detector, Analytica Chimica Acta 695, 110 (2011).

23. Q. Huang, S. Han, Y. Zhang, X. Qu, J. Fu, Z. Zhang, L. Ding, Y. Qian, X. Zhao, G. Huang, Novel micro-nanofluidic chip and device for fast identifying pathogenic bacteria, Journal of Computational and Theoretical Nanoscience 12, 1-6 (2015). 